\title{
A new locus for arrhythmogenic right ventricular cardiomyopathy (ARVD2) maps to chromosome 1q42-q43
}

\author{
Alessandra Rampazzo, Andrea Nava', Paul Erne ${ }^{2}$, Marc Eberhard ${ }^{3}$, Elisa Vian, Paola Slomp, Natascia Tiso, \\ Gaetano Thiene ${ }^{4}$ and Gian Antonio Danieli ${ }^{*}$ \\ Department of Biology, 'Department of Cardiology and ${ }^{4}$ Department of Pathology, University of Padua, Italy, ${ }^{2}$ Division of Cardiology, \\ Kantonsspital, Luzern and ${ }^{3}$ Department of Research, University Hospital, Basel, Switzerland
}

Received April 4, 1995; Revised and Accepted July 28, 1995

\begin{abstract}
Autosomal dominant arrhythmogenic right ventricular cardiomyopathy (ARVD, MIM 107970) is one of the major causes of juvenile sudden death. We have previously assigned the disease locus to chromosome 14q23-q24. Here we report on a novel variant of ARVD, which is transmitted associated to 1q42q43 and is characterized by a concealed form, showing effort-induced polymorphic tachycardias. Since both loci ARVD1 and ARVD2 map in proximity of $\alpha$-actinin genes, the possible implication of these myofibrillar proteins in the pathogenesis of ARVD is discussed. Two additional ARVD families, tested with markers of chromosomes 1q42-q43 and 14q23-q24, failed to show linkage, providing evidence of further genetic heterogeneity.
\end{abstract}

\section{INTRODUCTION}

Arrhythmogenic right ventricular cardiomyopathy (formerly arrhythmogenic right ventricular dysplasia, ARVD, MIM 107970) is inherited as autosomal dominant with reduced penetrance and it is one of the major genetic causes of juvenile sudden death $(1,2)$.

ARVD is characterized by a degenerative process, mostly involving the right ventricle, where the myocardium is replaced by adipose and connective tissue (3). The presence of these masses of fibro-fatty substitution accounts for the electrical instability which causes ventricular arrhythmias (4).

The degenerative process extends gradually to the whole ventricle wall, which becomes thinner than normal and in some cases may develop ventricular aneurysms. The diagnostic criteria of ARVD were recently established by an international cooperative effort (5). The prevalence of the disease is estimated to range from $6 / 10000$ in the general population to $4.4 /$ 1000 in some areas (6). Recently, on the basis of a linkage study on two Italian families, we assigned the ARVD locus to chromosome 14q23-q24 (6). Here we present evidence, based on a linkage study on three ARVD families, for the existence of a second locus (ARVD2), carried by chromosome 1 (1q42$\mathrm{q} 43$ ), and for further genetic heterogeneity.

\section{RESULTS}

In order to refine the chromosomal localization of ARVD, three additional ARVD families were collected, one in Switzerland (no. 101) and two in north east Italy (nos 102 and 103) (Fig. 1). The clinical features of the affected subjects belonging to these families satisfied the current diagnostic criteria for ARVD (5), in spite of the relevant interfamilial variability in the manifestation of the disease.

In family 101 the clinical presentation was typical of ARVD, with variable severity of the affection. Two subjects encountered sudden death. Among 30 subjects which underwent thorough cardiological study, 11 were diagnosed as affected with ARVD; four patients showed sustained ventricular tachycardias with left-branch block pattern, in five cases only minor arrhythmias were present, whereas in two other subjects no clinical symptoms were evident before cardiological examination.

In family 102 the disease occurred in a concealed form; all the affected members showed no change in heart size, normal standard ECG and functional capacity, but they consistently showed effort-induced polymorphic ventricular tachycardias. Four cases of juvenile sudden death were reported. Postmortem examination of two of these subjects showed a right ventricle of normal size, with no overt abnormalities. However large areas of fatty-fibrous replacement, mostly localized in the sub-epicardial layer of the right ventricle, were detected at the histological level.

Family 103 showed one case of juvenile sudden death. Postmortem examination detected typical ARVD features at the morphological and histological level. The affected subjects did not show major ventricular arrhythmias, but they invariably manifested a conduction defect with right branch block and left axial deviation.

ARVD was previously located in $14 \mathrm{q} 23-\mathrm{q} 24$, in the same chromosomal region where genes for $\alpha$-actinin 1 and $\beta$-spectrin (7) were mapped. Unexpectedly, negative lod scores were obtained in all three families tested with markers of that region (D14S42, D14S279 and D14S254) (Table 1).

Muscle-specific $\alpha$-actinin genes map to chromosome lq42q43 (ACTN2) (8) and to chromosome 11q13-q14 (ACTN3), respectively (8), whereas the gene coding for the non-erythroid 


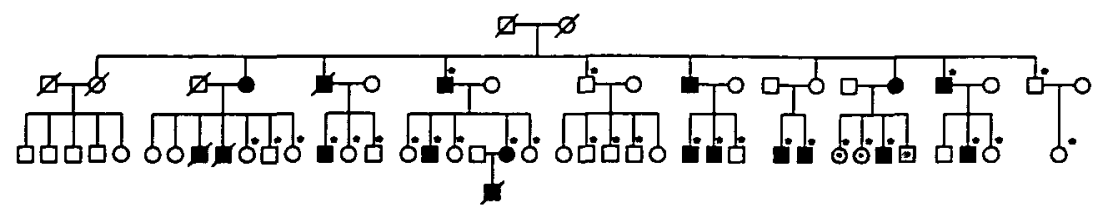

FAMILY 101

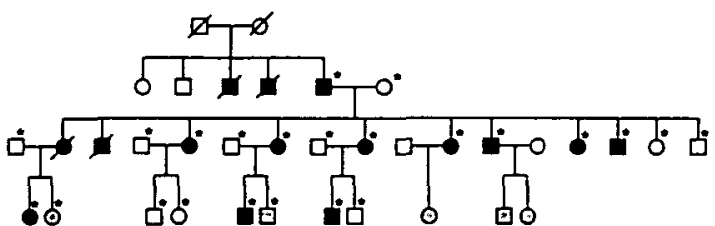

FAMILY 102

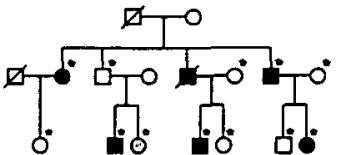

FAMILY 103

Figure 1. Pedigrees of three families with recurrent arrhythmogenic right ventricular cardiomyopathy. The members of the families from whom a DNA sample was obtained are marked by an asterisk.

Table 1. Two-point lod scores for different values of recombination fraction for three markers (D14S42, D14S279, D14S254) of the chromosome 14q24.3 in the three different families with recurrence of ARVD cases, reported in Fig. 1

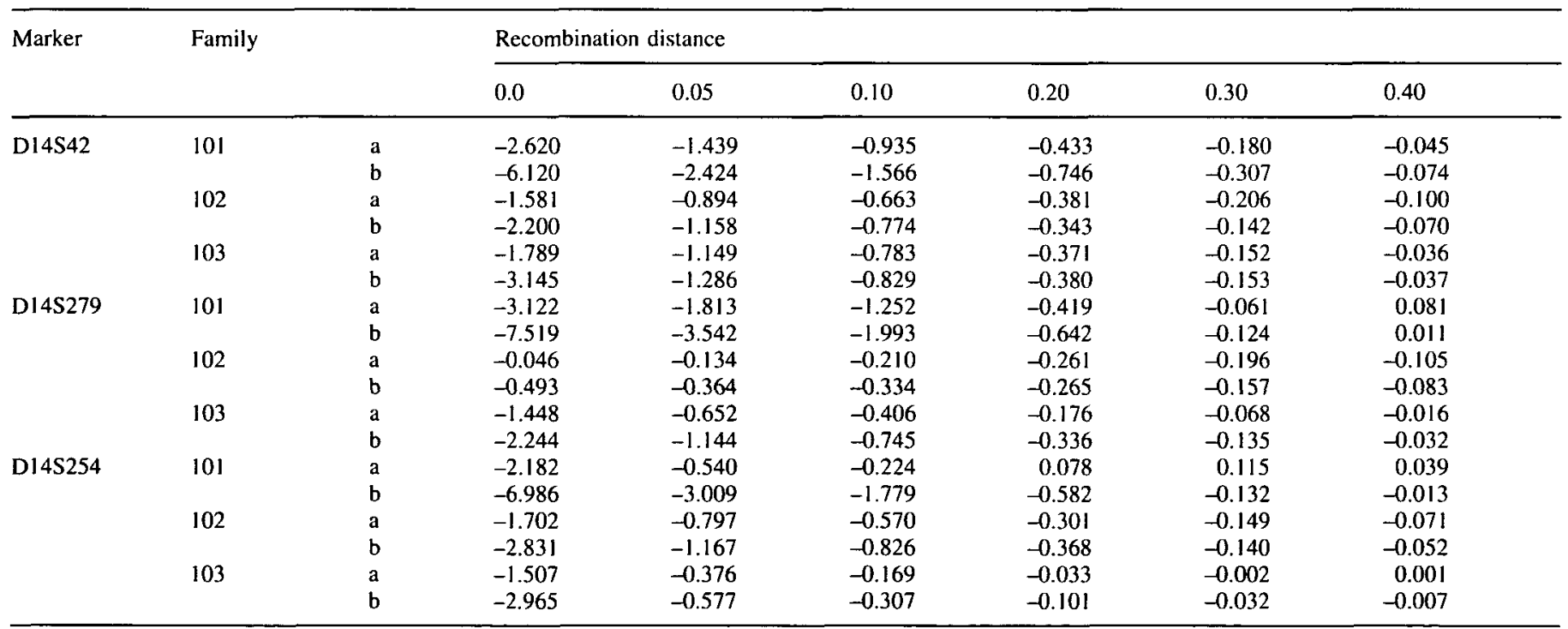

Lod scores were calculated for two different values of penetrance: $a=0.7 ; b=0.95$

$\beta$-spectrin (SPTBN1) maps to chromosome 2p21 (9). Therefore, the possible linkage of ARVD with each one of these genes was analyzed in the above families. Family 102 showed significantly positive lod score with the marker ACTN2 (a CA repeat polymorphism within the $\alpha$-actinin 2 gene). For such a marker, a lod score of 4.02 was obtained at $\theta=0.0$, assuming $95 \%$ penetrance. The lod score resulted 3.32 at $\theta=0.0$, when $70 \%$ penetrance was assumed. The same family showed significantly positive lod scores for markers flanking the ACTN2 gene (Table 2). By the multipoint linkage analysis a 
Table 2. Two-point lod scores for different values of recombination fraction for seven markers (DIS178, DISI79, D1S163, ACTN2, D1S184, D1S180 and DIS102) of the chromosome 1q42-q43 in the family no. 102, reported in Fig. 1

\begin{tabular}{|c|c|c|c|c|c|c|c|c|c|c|}
\hline Marker & Position & & \multicolumn{6}{|c|}{ Recombination fraction } & $\theta_{\max }$ & $z_{\max }$ \\
\hline & & b & 0.634 & 0.585 & 0.533 & 0.422 & 0.299 & 0.160 & 0.00 & 0.634 \\
\hline \multirow[t]{2}{*}{ DIS179 } & $1 \mathrm{q} 42-\mathrm{q} 43$ & $\mathbf{a}$ & 2.070 & 1.864 & 1.650 & 1.195 & 0.710 & 0.239 & 0.00 & 2.070 \\
\hline & & b & 2.484 & 2.265 & 2.036 & 1.542 & 0.995 & 0.397 & 0.00 & 2.484 \\
\hline DISI63 & $1 q 42-q 43$ & $\mathbf{a}$ & 3.708 & 3.386 & 3.049 & 2.322 & 1.518 & 0.659 & 0.00 & 3.708 \\
\hline & & $b$ & 4.021 & 3.693 & 3.347 & 2.596 & 2.186 & 0.793 & 0.00 & 4.021 \\
\hline \multirow[t]{2}{*}{ D1S184 } & lq42-q43 & $\mathrm{a}$ & 3.708 & 3.386 & 3.049 & 2.322 & 1.518 & 0.659 & 0.00 & 3.708 \\
\hline & & b & 4.395 & 4.044 & 3.675 & 2.871 & 1.964 & 0.929 & 0.00 & 4.395 \\
\hline \multirow[t]{2}{*}{ D1S180 } & $1 q 42-q 43$ & $\mathbf{a}$ & -1.302 & -0.829 & -0.609 & -0.356 & -0.199 & -0.087 & 0.45 & -0.041 \\
\hline & & b & -2.483 & -0.985 & -0.691 & -0.394 & -0.219 & -0.095 & 0.45 & -0.045 \\
\hline \multirow{2}{*}{ DIS102 } & $1 q 42-q 43$ & $\mathrm{a}$ & -0.733 & -0.056 & 0.127 & 0.239 & 0.223 & 0.138 & 0.20 & 0.239 \\
\hline & & b & -1.487 & 0.080 & 0.285 & 0.385 & 0.337 & 0.204 & 0.20 & 0.385 \\
\hline
\end{tabular}

Lod scores were calculated for two different values of penetrance: $a=0.7 ; b=0.95$.

peak (5.02) was obtained in correspondence of the marker ACTN2 (Fig. 2).

In contrast, the linkage study performed using the same markers on families 101 and 103 produced negative lod scores. Negative results were obtained also by using markers DIIS876, INT2 and TYRSIN, flanking the location of ACTN3 (1Iq1311q14) and D2S149, D2S162 and D2S170, which are associated to SPTBN1 (2p21) (data not shown).

\section{DISCUSSION}

In the present study, linkage was detected between ARVD and region 1q42-q43 in one Italian family where the disease segregated independently from markers of chromosome $14 q 23-q 24$.

The peculiar presentation of the disease in this family was outlined in a previous paper (10). Although all the affected subjects satisfied the current diagnostic criteria for ARVD (5), the unusual presence of effort-induced polymorphic tachycardias suggested a possible genetic heterogeneity. Linkage data confirmed that this form is genetically different from ARVD1. Accordingly, we suggest the name of ARVD2 for the 'concealed form showing effort-induced tachycardias'.

In family 102 ARVD2 is transmitted closely associated to $\alpha$-actinin2. Although the $95 \%$ confidence interval is wide (more than $20 \mathrm{cM}$ ), the hypothesis that $\alpha$-actinin2 may be involved in the pathogenesis of ARVD deserves consideration, since ARVDI, in turn, was mapped within the interval of the $\alpha$-actinin I locus.

Actinin-rich nemaline bodies were observed in the myocardium and in the skeletal muscle of one case of fatal cardiomyopathy, reported in a 29 year old woman showing no neuromuscular symptoms, whose mother and one sister suffered unexplained sudden death at ages 47 and 37 respectively (11). However, the involvement of actinin in the development of this cardiomyopathy was not proved.

Mutations in different genes coding for myofibrillar protein are involved in the pathogenesis of familial hypertrophic cardiomyopathy $(12,13)$. Among myofibrillar proteins, actinins, which belong to the spectrin superfamily, show strong structural

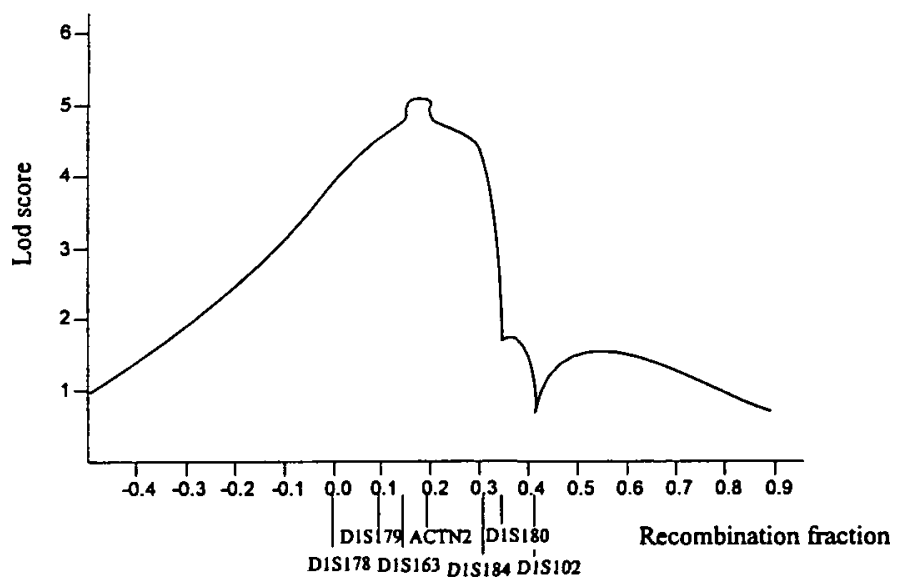

Figure 2. Eight-point linkage analysis of the ARVD family no. 102, with respect to seven marker loci. For the calculations, a $95 \%$ penetrance was assumed.

similarity with the $\mathrm{NH}_{2}$ domain of dystrophin (14). It is noteworthy that the degenerative process taking place in the myocardium is similar in ARVD and in Duchenne-Becker muscular dystrophy, where a cardiomyopathy frequently develops as a primary consequence of some dystrophin mutations (15-17). Therefore, the involvement of actinins in the pathogenesis of ARVD might be reasonably suspected.

However, the possibility that ARVD is caused by mutations in a different gene, closely linked to $\alpha$-actinin, must be seriously considered. Actinin genes are very conserved through biological evolution (7) and multigene families are often characterized by clustering of sequences showing high structural and functional similarity. Therefore, the existence of a yet unknown gene, closely linked and functionally related to actinin, cannot be excluded.

Among the two families with no linkage with markers associated with ACTN1 or ACTN2 genes, family 103 showed an interesting and peculiar association of ARVD with a conduction defect. This might correspond to a new clinical 
entity. Unfortunately, a linkage simulation conducted on this family produced a maximum expected lod score below 2.0. Therefore the investigation on this potentially novel form of ARVD is for the moment precluded. On the other hand, the different manifestation of the disease in this family with respect to family 101 indicates that the two forms may be genetically heterogeneous. Hence, it is likely that another gene(s), in addition to ARVD1 and ARVD2, is independently involved in the pathogenesis of arrhythmogenic right ventricular cardiomyopathy.

\section{MATERIALS AND METHODS}

\section{Families}

Two families with recurrence of ARVD, from the Padua district, were identified at the Department of Cardiology of the University of Padova (Italy). Another family, from a Swiss Alps valley, was diagnosed at the Cardiology Department of the Luzern Kantonsspital (Switzerland).

\section{Diagnostic criteria}

International cooperation led to the establishment of diagnostic criteria for ARVD (5). The major criteria included: familial disease diagnosed according to autopsy or surgery, discrete myocardial atrophy with fibro-fatty replacement of myocardium on endomyocardial biopsy, sustained left bundle branch block type ventricular tachycardia, severe global dilatation and reduction of right ventricular ejection fraction with no left ventricular impairment or severe regional dilatation of the right ventricle, right ventricular aneurysms, epsilon waves or localized prolongation (>110 ms) of the QRS in right precordial leads (V1-V3). Minor criteria were: family history of premature sudden death ( $<35$ years) due to suspected right ventricular dysplasia, non-sustained left bundle branch block type ventricular tachycardia, frequent monomorphic or polymorphic extrasystoles left bundle branch block type, mild global right ventricular dilatation and/or ejection fraction reduction, mild regional dilatation of the right ventricle, regional right ventricular hypokinesia, late potentials (signal averaged ECG), inverted T-waves in precordial leads.

Diagnosis of ARVD is fulfilled by the presence of two major criteria or one major plus two minor criteria or four minor criteria.

\section{Genotyping}

Genomic DNA from available family members was extracted from blood samples according to the salting out procedure. DNA samples were analyzed by polymerase chain reaction (PCR) using markers obtained from the Généthon list of microsatellites (18) or commercially available from ISOGEN BIOSCIENCE (Netherlands). The amplified PCR products were denatured and separated on a $9 \%$ denaturing polyacrylamide gel. The gels were silver stained and dried.

Linkage analysis

The two-point linkage analyses were performed with the computer program MLINK from the LINKAGE program (version 5.2) (19). For the multipoint analyses the programs FASTLINK $(20,21)$ and FASTMAP(22) were used, run on a SUN (SPARC 10) computer.

\section{ACKNOWLEDGEMENTS}

The work was supported by TELETHON-Italy (grant no. 527 to A.Nava), by the Italian National Research Council (CNR-FATMA Project) and by the Health Department of the Veneto Region. P.E. and M.E. were supported by Swiss National Foundation 32-039 446.93. The invaluable cooperation of Mrs P.Marcon is gratefully acknowledged. We thank Dr C.Montecucco (Padua) for helpful criticisms of the manuscript.

\section{REFERENCES}

1. Corrado, D., Thiene, G., Nava, A., Rossi, L., Pennelli, N. (1990) Am. J. Med., 89, 588-596.

2. Nava, A., Thiene, G., Canciani, B., Scognamiglio, R., Daliento, L., Buja, G., Martini, B., Stritoni, P., Fasoli, G. (1988) J. Am. Coll. Cardiol., $12,1222-1228$
3. Thiene, G., Nava, A., Corrado, D., Rossi, L., Pennelli, N. (1988) New Engl. J. Med., 318, 129-133.

4. Marcus, F.I., Fontaine, G.H., Guiraudon, G., Frank, R., Laurenceau, J.L., Malergue, C., Grosgogeat, Y. (1982) Circulation, 65, 384-398

5. McKenna, W.J., Thiene, G., Nava, A., Blomstrom-Lundqvist, C., Fontaine, G., Camerini, F. (1994) Br. Heart J., 71, 215-218.

6. Rampazzo, A., Nava, A., Danieli, G.A., Buja, G., Daliento, L., Fasoli, G., Scognamiglio, R., Corrado, D., Thiene, G. (1994) Hum. Mol. Genet., 3, 959-962.

7. Youssouffian, H., McAfee, M. and Kwiatkowski, D.J. (1990) Am. J. Hum. Genet., 47, 62-72

8. Beggs, A.H., Byers, T.J., Knoll, J.H., Boyce, F.M., Bruns, G.A.P., Kunkel, L.M. (1992) J. Biol. Chem., 267, 9281-9288

9. Chang, J.G., Scarpa, A., Eddy, R.L., Byers, M.G., Harris, A.S., Morrow, G.S., Watkins, P., Shows, T.V., Forget, B.G. (1993) Genomics, $17,287-293$

10. Nava, A., Canciani, B., Daliento, L., Miraglia, G., Buja, G., Fasoli, G., Martini, B., Scognamiglio, R., Thiene, G. (1988) Internat. J. Cardiol., 21, 111-123.

11. Meier, C., Gertsch, M., Zimmerman, A., Voellmy, W., Geissbuhler, J. (1983) New Engl. J. Med., 308, 1536-1537

12. Geisterfer-Lowrance, A.A.T., Kass, S., Tanigawa, G., Vosberg, H.P., McKenna, W., Seidman, C.E., Seidman, J.G. (1990) Cell, 62, 999-1006.

13. Thierfelder, L., Watkins, H., Macrae, C., Lamas, R., McKenna, W., Vosberg, H.P., Seidman, J.G., Seidman, C.E. (1994) Cell, 77, 701- 712.

14. Blanchard, A., Ohanian, V., Critchley, D. (1989) J. Muscie Res. Cell Motil., 10, 280-289

15. Muntoni, F., Cau, M., Ganau, A., Congiu, R., Arvedi, G., Mateddu, A., Marrosu, M.G., Realdi, G., Cao, A., Melis, M.A. (1993) New Engl. J. Med., 329, 921-925

16. Yoshida, K., Ikeda, S.I., Nakamura, A., Kagoshima, M., Takeda, S., Shoji, S., Yanagisawa, N. (1993) Muscle and Nerve, 16, 1161-1166

17. Melacini, P., Fanin, M., Danieli, G.A., Fasoli, G., Villanova, C., Angelini, C., Vitiello, L., Miorelli, M., Buja, G., Mostacciuolo, M.L., Pegoraro, E., Dalla Volta, S. (1993) J. Am. Coll. Cardiol., 22, 1927-1934

18. Gyapay G., Morissette J., Vignal A., Dib C., Fizames C., Millasseau P., Marc S., Bernardi G., Lathrop M., Weissenbach J. (1994) Nature Genet., 7, 246-339.

19. Lathrop G.M., Lalouel J.M. (1984) Am. J. Hum. Genet., 36, 460- 465.

20. Cottingham, R.W., Idury, R.M., Schaffer, A.A. (1993) Am. J. Hum. Genet., 53, 252-263.

21. Schaffer, A.A., Gupta, S.K., Shriram, K., Cottingham, R.W. (1994) Hum. Hered. 44, 225-237.

22. Curtis, D., Gurling, H. (1993) Hum. Hered., 43, 173-185. 